\title{
A Case of Malignant Solitary Fibrous Tumor of the Skin
}

\author{
Kihyuk Shin ${ }^{1}$, Tae-Wook Kim ${ }^{1}$, Hyun-Joo Lee ${ }^{1,2}$, Sung-Min Park ${ }^{1}$, Hyunju Jin ${ }^{1}$, Woo-Haing Shim ${ }^{1}$, \\ Gun-Wook Kim ${ }^{1,2}$, Hoon-Soo Kim ${ }^{1,2}$, Hyun-Chang $\mathrm{Ko}^{1}$, Byung-Soo Kim ${ }^{1,2}$, Moon-Bum Kim ${ }^{1,2}$, \\ Hyang-Suk You, ${ }^{1,2}$ \\ ${ }^{1}$ Department of Dermatology, Pusan National University School of Medicine, ${ }^{2}$ Biomedical Research Institute, Pusan National University \\ Hospital, Busan, Korea
}

\section{Dear Editor:}

Solitary fibrous tumor (SFT) is uncommon fibroblastic mesenchymal tumor that commonly affects pleura and peritoneum ${ }^{1}$. Despite multiple reports of SFT in various organs, cutaneous SFT is rare and few case reports have been issued. Furthermore, malignant cutaneous SFT is exceptional $^{2}$. To our knowledge, this is only the second report of malignant SFT of the skin. We received the patient's consent form about publishing all photographic materials.

A 59-year-old man presented with a protruding mass on his right shoulder, which had grown slowly over 10 years. The $5.0 \times 4.3 \mathrm{~cm}$-sized tumor was relatively hard and telangiectasia was observed on its surface (Fig. 1A, B). The patient did not complain of lesion-associated pain or itching. Other than the skin lesion, a physical examination revealed no other abnormality. On ultrasonography, a heterogeneous echogenic mass with internal vascularity was observed. An excisional biopsy was performed, and during excision no connection was observed between the tumor and other organs.

Grossly the tumor was well-circumscribed (Fig. 1C), and histopathologic examination revealed an unencapsulated hypercellular tumor composed of a haphazard pattern of proliferating spindle cells embedded in fibrotic stroma (Fig. 2A, B). Cells were characterized by pleomorphism and a mitotic rate of 34 mitotic figures per 10 high-power fields (HPFs) (Fig. 2C). On immunohistochemical exami-
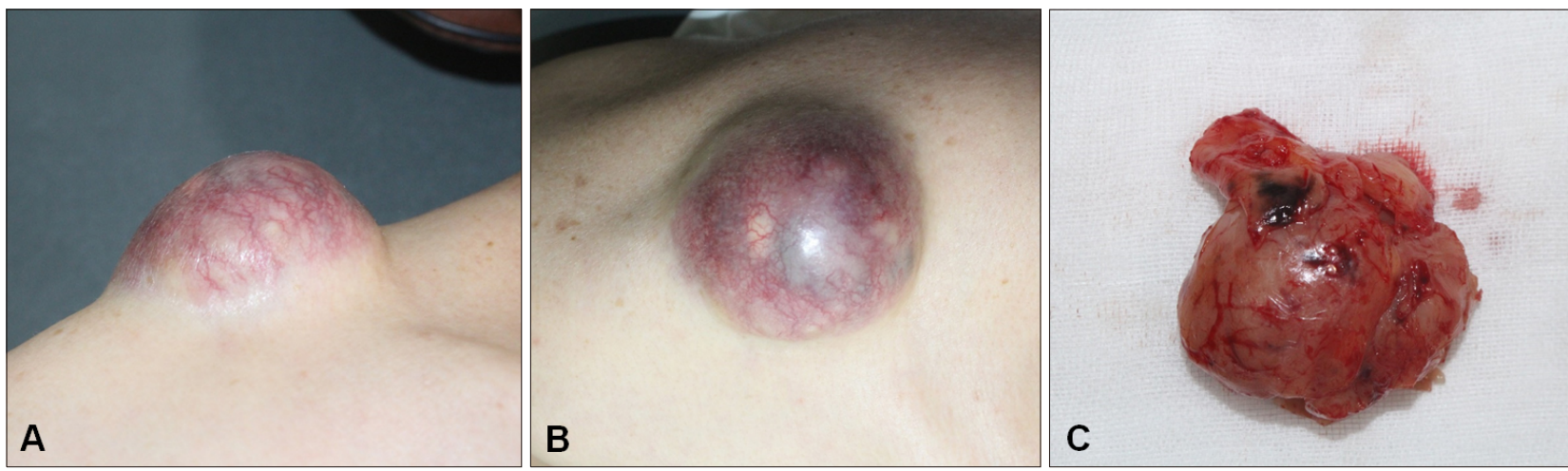

Fig. 1. (A, B) A $5.0 \times 4.3 \mathrm{~cm}$-sized protruding mass on the right shoulder and (C) gross features of the excised tumor.

Received January 19, 2018, Revised March 7, 2018, Accepted for publication March 14, 2018

Corresponding author: Hyang-Suk You, Department of Dermatology, Pusan National University Hospital, 179 Gudeok-ro, Seo-gu, Busan 49241, Korea. Tel: 82-51-240-7338, Fax: 82-51-245-9467, E-mail: oasis8299@naver.com ORCID: https://orcid.org/0000-0002-1697-397X

This is an Open Access article distributed under the terms of the Creative Commons Attribution Non-Commercial License (http://creativecommons.org/ licenses/by-nc/4.0) which permits unrestricted non-commercial use, distribution, and reproduction in any medium, provided the original work is properly cited.

Copyright $($ The Korean Dermatological Association and The Korean Society for Investigative Dermatology 


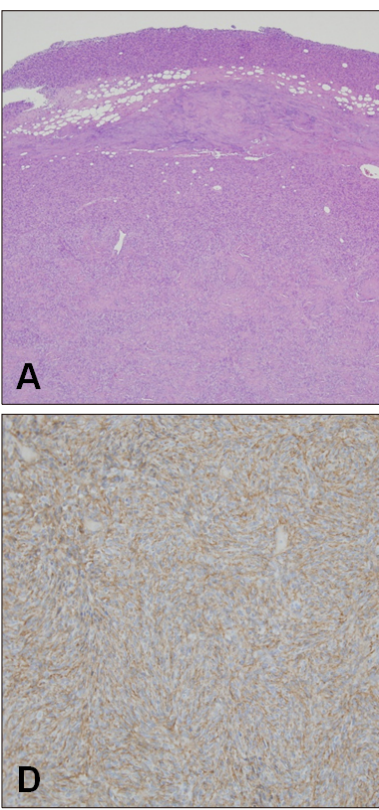

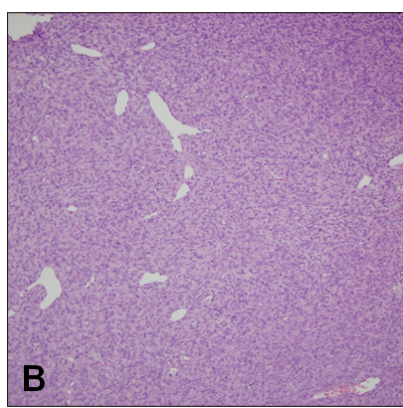
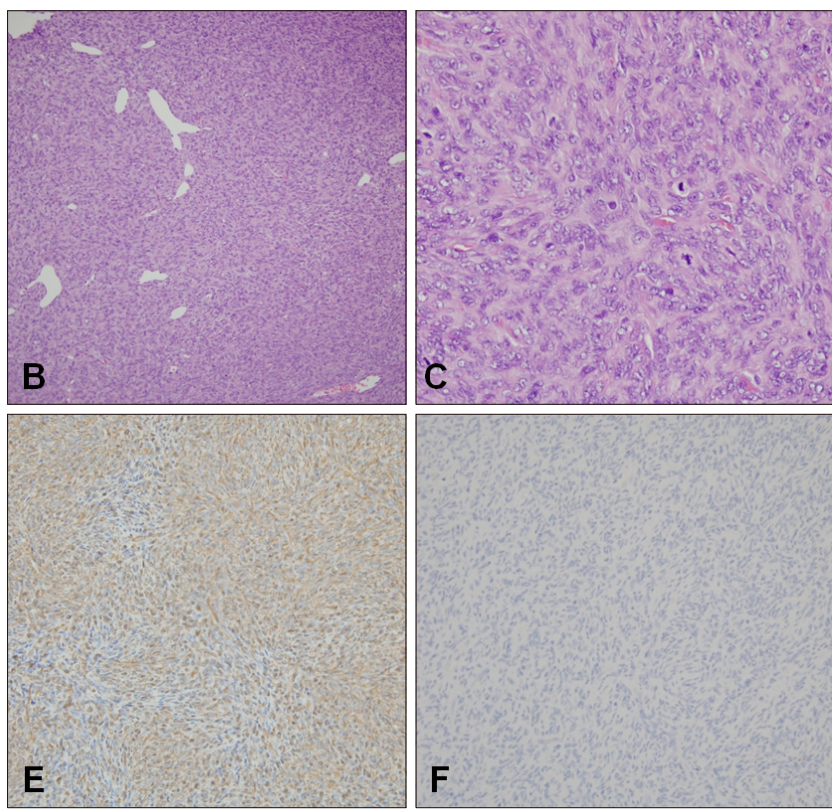

Fig. 2. Histopathologic findings of the tumor mass. (A) The tumor was well circumscribed and unencapsulated $(\mathrm{H} \& \mathrm{E}, \times 40)$. (B) Image showing proliferation of spindle cells in a haphazard manner $(\mathrm{H} \& \mathrm{E}, \times 100)$. (C) Photomicrograph showing mitotic activity and cellular atypia $(\mathrm{H} \& \mathrm{E}, \times 400)$. The tumor cells were strongly positive for (D) CD34 $(\times 200)$ and $(E)$ vimentin $(\times 200)$, and negative for $(F)$ S100 $(\times 200)$. nation, tumor cells were strongly positive for CD34 and vimentin, and negative for cytokeratin, desmin, S100, and smooth muscle actin (Fig. 2D F). These clinico-histopathologic findings were consistent with malignant SFT of the skin and the patient was transferred to our oncology department for chemotherapy.

Although SFT is a spindle cell tumor which were initially described as pleural tumors, and most involve visceral pleura, though extrapleural involvement has been well described $^{3}$. SFT is a type of spindle cell tumor, and cutaneous SFT is extremely rare. Cutaneous SFT has been described as a superficial, painless mass often misdiagnosed as a lipoma or epidermal cyst clinically. Histologically, SFT is classified as storiform, herring-bone, hemangiopericytic, neural-type palisading, or diffuse sclerosing, and the spindle cells of SFTs exhibited "patternless" proliferation with thick collagen bundles arranged in the stroma ${ }^{4}$. The varied histologic features of SFT can generate a broad histologic differential diagnoses, which include dermatofibroma, dermatofibrosarcoma protuberans, smooth muscle tumors, spindle cell lipoma, hemangiopericytoma, benign peripheral nerve sheath tumors, melanoma, and cutaneous myofibroma. Immunohistochemical studies are helpful because SFTs are typically reactive for CD34 and vimentin, but not for cytokeratins, smooth muscle actin, CD31, S100, and CD68 ${ }^{5}$.

Most SFTs are clinically benign, but approximately $5 \% \sim 10 \%$ show local recurrence and/or metastasis ${ }^{2}$. Although the histologic criteria for malignant SFTs are controversial, tumor size $>5 \mathrm{~cm}$, dense cellularity, infiltrative growth, pleomorphism, mitotic indices $>4$ per $10 \mathrm{HPFs}$, and necrosis are generally considered worrisome. In the current case, the tumor showed all of these features. Histopathologically malignant SFT is extremely rare, and to date, only one report on histopathologically malignant SFT of the skin has been issued ${ }^{2}$. Prognosis and treatment options for cutaneous malignant SFTs remain uncertain, therefore, further clinicopathologic studies are required on more cases with longer clinical follow ups.

\section{CONFLICTS OF INTEREST}

The authors have nothing to disclose.

\section{ORCID}

Kihyuk Shin, https://orcid.org/0000-0001-8955-9828

Tae-Wook Kim, https://orcid.org/0000-0002-8138-7993

Hyun-Joo Lee, https://orcid.org/0000-0002-1696-0976

Sung-Min Park, https://orcid.org/0000-0002-4915-8111

Hyunju Jin, https://orcid.org/0000-0002-0343-1629

Woo-Haing Shim, https://orcid.org/0000-0002-5182-5294

Gun-Wook Kim, https://orcid.org/0000-0003-1599-7045

Hoon-Soo Kim, https://orcid.org/0000-0002-7649-1446

Hyun-Chang Ko, https://orcid.org/0000-0002-3459-5474

Byung-Soo Kim, https://orcid.org/0000-0003-0054-8570

Moon-Bum Kim, https://orcid.org/0000-0003-4837-0214

Hyang-Suk You, https://orcid.org/0000-0002-1697-397X

\section{REFERENCES}

1. Mena H, Ribas JL, Pezeshkpour GH, Cowan DN, Parisi JE. 
Brief Report

Hemangiopericytoma of the central nervous system: a review of 94 cases. Hum Pathol 1991;22:84-91.

2. Creytens D, Ferdinande L, Van Dorpe J. Histopathologically malignant solitary fibrous tumor of the skin: a report of an unusual case. J Cutan Pathol 2016;43:629-631.

3. Chan JK. Solitary fibrous tumour--everywhere, and a diagnosis in vogue. Histopathology 1997;31:568-576.
4. Hardisson D, Cuevas-Santos J, Contreras F. Solitary fibrous tumor of the skin. J Am Acad Dermatol 2002;46(2 Suppl Case Reports):S37-S40.

5. Soldano AC, Meehan SA. Cutaneous solitary fibrous tumor: a report of 2 cases and review of the literature. Am J Dermatopathol 2008;30:54-58.

\title{
Impairment of Hair-Inducing Capacity of Three-Dimensionally Cultured Human Dermal Papilla Cells by the Ablation of STAT5
}

\author{
Chang Hoon Seo, Mi Hee Kwack ${ }^{1}$, Moon Kyu Kim ${ }^{1}$, Jung Chul Kim ${ }^{1}$, Young Kwan Sung ${ }^{1}$ \\ New Drug Development Center, Daegu-Gyeongbuk Medical Innovation Foundation, ${ }^{1}$ Department of Immunology, School of Medicine, \\ Kyungpook National University, Daegu, Korea
}

Dear Editor:

The dermal papilla (DP) of hair follicle is essential for hair morphogenesis, growth, and regeneration. Therefore, DP cells are considered to be an optimal cell source for genesis of new hair follicles ${ }^{1,2}$. However, there remains an experimental challenge resulting from DP cells gradually losing their hair-inductive capacity when cultured two-dimensionally (2D) ${ }^{3}$. Three-dimensional (3D) spheroid culturing was successfully employed to overcome the loss of hair inductivity of 2D-cultured human DP cells ${ }^{4-6}$.

STAT5 is a signal transducer and activator of transcription (STAT). Recently, Legrand et al. ${ }^{7}$ reported that the actived form of STAT5 (phospho-STAT5; P-STAT5) is restricted to the DP cells and activation of STAT5 in the DP plays an important role in hair growth phase induction. They showed that hair-inductive capacity of mouse DP-derived multi- potent stem cells, skin-derived precursors, is significantly enhanced by adenoviral overexpression of STAT5A or $\mathrm{STAT}_{5 \mathrm{~B}}{ }^{7}$. In line with this, STAT5 deletion impaired formation of de novo hair follicles in skin-derived precursors $^{7}$. In contrast, Harel et al. ${ }^{8}$ reported that the hair inductivity of human DP spheres is enhanced by the treatment with tofacitinib, a STAT signaling inhibitor. These controversial reports prompted us to investigate role of STAT5 in the hair inductivity of human DP cells. We performed STAT5 knock-down in human DP spheres and the spheres were implanted into the back of the nude mice together with mouse epidermal cells.

The Medical Ethical Committee of the Kyungpook National University Hospital (Daegu, Korea) approved all of the described studies (IRB no. KNUH 2013-02-001-007). Student's t-test was used to analyze differences between groups us-

\footnotetext{
Received December 19, 2017, Revised February 13, 2018, Accepted for publication March 21, 2018
}

Corresponding author: Young Kwan Sung, Department of Immunology, School of Medicine, Kyungpook National University, 680 Gukchaebosang-ro, Jung-gu, Daegu 41944, Korea. Tel: 82-53-420-4874, Fax: 82-53-661-3133, E-mail: ysung@knu.ac.kr ORCID: https://orcid.org/0000-0002-5122-4616

This is an Open Access article distributed under the terms of the Creative Commons Attribution Non-Commercial License (http://creativecommons.org/ licenses/by-nc/4.0) which permits unrestricted non-commercial use, distribution, and reproduction in any medium, provided the original work is properly cited.

Copyright (C) The Korean Dermatological Association and The Korean Society for Investigative Dermatology 